\title{
The Development of Virtual World Tools to Enhance Learning and Real World Decision Making in the Australian Sugar Farming Industry
}

http://dx.doi.org/10.3991/ijac.v7i3.4002

\author{
Kathryn Reardon-Smith ${ }^{1}$, Helen Farley ${ }^{1}$, Neil Cliffe ${ }^{1}$, Shahbaz Mushtaq ${ }^{1}$, Roger Stone ${ }^{1}$, Joanne Doyle ${ }^{1}$, Neil \\ Martin $^{1}$, Jenny Ostini ${ }^{1}$, Tek Maraseni ${ }^{1}$, Torben Marcussen ${ }^{1}$, Adam Loch ${ }^{2}$, Janette Lindesay ${ }^{3}$ \\ ${ }^{1}$ University of Southern Queensland, Toowoomba QLD Australia \\ ${ }^{2}$ University of South Australia, Adelaide SA Australia \\ ${ }^{3}$ Australian National University, Canberra ACT Australia
}

\begin{abstract}
In farming, the outcome of critical decisions to enhance productivity and profitability, and so ensure the viability of farming enterprises, is often influenced by seasonal conditions and weather events over the growing season. This paper reports on a project that uses cutting-edge advances in digital technologies, and their application in learning environments, to develop and evaluate a web-based virtual 'discussion-support' system for improved climate risk management in Australian sugar farming systems. Customized scripted video clips (machinima) are created in the Second Life virtual world environment. The videos use contextualized settings and lifelike avatar actors to model conversations about climate risk and key farm operational decisions relevant to the real-world lives and practices of sugarcane farmers. The tools generate new cognitive schema for farmers to access and provide stimuli for discussions around how to incorporate an understanding of climate risk into operational decision-making. They also have potential to provide cost-effective agricultural extension that simulates real world face-to-face extension services, but is accessible anytime anywhere.
\end{abstract}

Index Terms-agricultural extension, climate risk management, discussion support tools, Second Life machinima.

\section{INTRODUCTION}

Digital technologies serve a vital role in the costeffective delivery and communication (extension) of agricultural information. In a world facing exponential population growth, increasingly uncertain climatic conditions, and looming food, water, and environmental insecurity, there is significant imperative for the ongoing development of agricultural extension approaches [1]. These need to capture leading edge advances in climate science, whilst also using the latest understandings from research into education and learning, in order to provide effective support for on-farm decision-making and risk management.

Adaptation to climate change occurs largely through action at the local level [2]. In regions where increasing climatic variability poses significant risk to farm profitability and viability, a good understanding of climate information is particularly important to on-farm decision making. Seasonal conditions and weather events over the growing season can have a significant impact on crop production. Hence, knowledge about how to use relevant climate information in risk-based operational decisionmaking is critical when making farm-level decisions (e.g. about cropping patterns, investment in fertilizers and pesticides, plant population densities, irrigation scheduling, and the timing of planting and harvesting activities).

\section{A. Agricultural extension}

Modern day agricultural knowledge is increasingly complex and, as a result, there is a tendency for its dissemination (extension) to be largely institutionalized, 'top down', and focused on technology transfer-delivering specific, often commodity-based, advice to farmers about the practices they should adopt to increase production and profit, and minimize environmental harm. Agricultural extension services increasingly include a range of interactive participatory and social learning approaches based on research evidence that knowledge exchange and adult learning are best achieved when farmers' existing knowledge and experience is acknowledged [3]. This understanding has also led to increased focus in the agricultural extension services space on experiential learning and farmer-to-farmer exchanges [4], as well as advocacy for public extension systems to operate within a farmerdriven "bottom up" agricultural innovations framework [5].

In particular, Francis and Carter [4] recommend that agricultural training programs be inclusive of all stakeholders, and that they acknowledge the complex framework of social, economic, and environmental factors at play in farmer decision-making. Their research also found that challenging, engaging, and entertaining activities have a positive learning outcome while discussions and reflection were also highly valuable [4]. Thus, there is significant imperative for ongoing improvement on conventional modes of agricultural extension. A key challenge is to develop new approaches, which incorporate these concepts and maximize the number of farmers reached in the most efficient, equitable, and cost-effective way.

Agricultural extension services reportedly deliver a good return on investment, resulting in a positive impact on practice change (e.g. the adoption of new technologies and more sustainable farm management practices). However, increasingly, they face a range of challenges, including: relatively small numbers of extension personnel relative to farmer needs and demands; variable levels of experience, training, and communication skills; and lack of 
operational resources (funds, equipment) due to declining levels of government funding and policy support [6]. In many parts of Australia, farmers' access to face-to-face extension services is further constrained by the oftenconsiderable distances, and associated time and costs involved.

There is also increasing imperative to scale-up agricultural and agri-climate extension to ensure benefit to millions of farmers globally. Developing more effective means of integrating aspects of climate forecasting into core farming decisions is an urgent consideration if farmers around the world are to remain sustainable and global food security is to be ensured. Advances in distance learning environments, and, in particular, "eLearning" involving the use of digital platforms, including virtual world environments to simulate real world decision making scenarios, indicate significant opportunity for the development of cost-effective agricultural e-extension systems $[7,8]$.

\section{B. Digital technologies in agricultural extension}

Digital technologies already serve a vital role in the delivery and communication of agricultural information. They provide a viable option with potential to complement and expand the reach of conventional extension services. Furthermore, increasingly sophisticated digital platforms, and their application in learning environments, in conjunction with anytime anywhere access to high speed internet, allow a range of novel approaches to be trialed as alternative information exchange methods for cost-effective agricultural extension.

Technological advances have led to the development of a range of sophisticated decision support tools, with links to operations research/management science, many of which use complex biophysical modeling to derive optimal solutions to particular farm management problems [9]. However, the adoption of such tools by farmers has been limited $[10,11,12]$. The reasons for this may include their limited capacity to incorporate either existing farmer knowledge or the range of contextual factors involved in farm management decision making (as identified by Francis and Carter [4], above).

The reported failure of decision support systems to effectively influence farm management decisions of large numbers of farmers has also led to revised thinking of the need for information to match farmers' needs and accommodate different styles of information gathering, reasoning, and decision-making [9, 12]. Close dialogue and collaboration with user groups is critical to the development of effective decision support for farmers [7, 12].

Increasingly, calls have been made for decision support systems to better engage with and mimic farmers' natural modes of learning through experience and discussion [13, 14] (Fig. 1). The concept of "kitchen table" discussions was developed whereby outputs of integrated climate-crop simulation were provided "face-to-face" by a visiting farming systems specialist to stimulate free discussions around key decisions that could have practical value to the farmers present [10]; however, there has been little apparent progress to date in developing more cost-effective approaches to facilitate this process and deploy the concept more widely - a role for which digital technologies appear to be ideally suited [7].

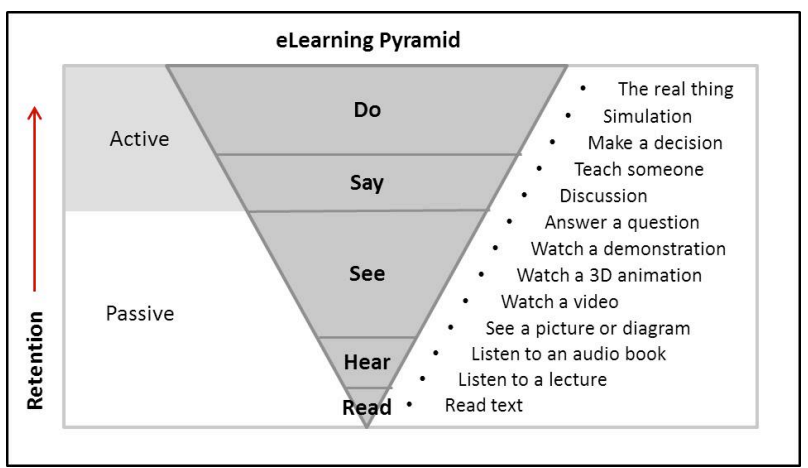

Figure 1. The eLearning Pyramid (after [14]) provides a conceptualization of the relative learning benefits associated with different agriextension approaches from simple, passive reading of relevant text through to active discussion and decision-making.

This paper reports on research, undertaken by our crossdisciplinary research team, to develop and evaluate a webbased virtual "discussion support" system for agri-climate extension. The system integrates relevant climate information with practical farming operations to support improved decision making around climate risk management and farming practices on Australian sugar cane farms using an innovative application of the web-based virtual world Second Life ${ }^{\mathrm{TM}}$ platform. There is also capacity to operationalize the "Sweet Success" tools for mobile technologies.

Digital discussion support tools trialed in this research are designed to provide contextually relevant information that may challenge farmers' current thinking and farm management practices. They may also stimulate discussion amongst farmers around how to better incorporate an understanding of climate risk into their decision making. We anticipate/hypothesize that the "Sweet Success" tools may work at a number of levels: they may stand alone as a potential catalyst for a change in thinking and practice; they may work with or without the presence of technical advisers or scientists to augment learning and promote group (including family unit) discussion; and, in some cases, they may also lead to the use of more complex decision support tools.

\section{VirTual TOOLS DEVElopMENT}

\section{A. The Second Life Virtual World Platform}

A virtual world [15] is a computer-, server- or internetbased virtual environment that allows participants to move around and use various forms of communication. It allows participants to create a virtual identity which persists beyond the initial session $[16,17]$. Second Life is one of the most well-known VWs in part due to the intense media scrutiny it has attracted, but predominantly because the content is created, almost exclusively, by users. At the time of writing, it boasts 37 million user accounts and up to 62,000 users online at any time [18].

VWs are populated by motional "avatars", a term derived from Sanskrit and used in Hindu mythology to denote the earthly form adopted by a deity, commonly Visnu [19]. In VWs, this term denotes the representation of a character, controlled either by an individual or a software agent in the case of a "bot", which acts somewhat like a virtual automaton [20]. The choice of avatar can reflect a wide range of identities, vocation, gender or ethnicity, all of which can be customised by the user. 
Second Life is a three-dimensional multi-user virtual world (VW) environment that enables the development of realistic simulated settings in which characters ("avatars") can move, interact, and form virtual communities [21]. Since 2003, Second Life has captured the imagination of the general public, despite some concern at the implications and complications for a first life. From an educational perspective, the flexibility of the Second Life virtual world platform offers significant imaginative possibilities where aspects can include virtual representations of learners and teachers as avatars [21, 22].

Second Life is also an ideal environment in which to shoot machinima (virtual world video clips) as users are able to manipulate the VW environment to create and customize an infinite variety of contexts and avatars. In this project, a set of machinima, filmed in Second Life, were developed as agri-climate discussion support tools to depict key decision points likely to be encountered by Australian sugarcane farmers. These machinima use lifelike avatar actors, customized settings, and real-world, climate-based scenarios relevant to the lives and practices of Australian sugarcane farmers.

\section{B. Developing Decision Scenarios}

The project team ultimately required a number of machinima for evaluation, each representing a key decision point in sugar cane farming. In order to ensure consistency throughout the series and an engaging integrated storyline, back stories were created for the main characters. These characters were based on the decision-making types described by Jørgensen and colleagues [12], namely (a) system-orientated farmers, (b) experience-based farmers and (c) advisory-orientated farmers [12]. As in real life, farmers' family members also play a part in the machinima.

Short (3-5 minute) scripted conversations (discussions) between these characters around key decision points in sugar cane farming were written by team members with knowledge of agricultural systems and particularly cane farming systems. These conversations are written around the real-world experiences of Australian sugarcane farmers. They include discussion of risks associated with variable weather conditions and different on-farm management options.

The approach taken in these machinima is essentially that of storytelling, noted by Tsou et al. [23] as a 'practical and powerful teaching tool', particularly in the context of peer collaboration [24]. Abma [25] describes learning within organizations as a 'collective and relational process' through which stories build knowledge and appreciation of issues, while digital storytelling is identified by Barrett [26] as a tool for 'deep learning'.

When writing the scripted conversations and developing the machinima, elements from the emerging theory of storytelling as learning and reflection on practice were borne in mind. Successful story telling must engage stakeholders on multiple levels, explore issues at scales which are relevant and credible to stakeholders at that scale [27], and be set in appropriate natural and social contexts [28]. They must also address an aesthetics perspective which generates feelings of meaning, connectedness, and enjoyment for its own sake [29, 30, 31].

\section{Developing Machinima in Second Life}

Much of the development of machinima, defined as 'filmmaking within a real-time, 3-D virtual environment, often using 3-D videogame technologies' [32], corresponds closely to the development of other video formats with real world actors. In this project, specialist Second Life builders and machinima makers, Top Dingo (www.topdingo.com), were engaged to create the avatars, craft the environment, and film and edit the machinima. Once the focus of the machinima had been decided, a scenario was envisaged and mapped out using a storyboard. As in the film industry, storyboarding provides a medium for communicating about moving compositions [33], and also helps to determine the resource requirements, actors (in this case, avatars) required, and appropriate environments for filming.

A prototype machinima was created to allow preliminary evaluation by the research team and a small focus group of potential users (sugar cane farmers, extension officers, and industry personnel) to fine-tune the machinima creation process. This involved the following steps:

1. The soundtrack to the machinima was recorded separately, by a professional sound engineer in a sound studio, at the University of Southern Queensland (USQ), with parts played by student actors enrolled in creative arts courses at USQ. This was seen as also having valuable pedagogical value and providing the added benefit of voiceover experience for the student actors.

2. Avatars for the project were created by Top Dingo according to the storyboard characters envisaged. Top Dingo collaborated with the project team to ensure that the avatars were believable in terms of age, appearance, and dress. Avatars and the clothes they wear were purchased from the Second Life Marketplace (https://marketplace.secondlife.com/) which acts as a storefront for Second Life builders to sell what they have created. These resources are often inexpensive and able to be adapted to suit a particular purpose.

3. A realistic setting was developed by Top Dingo. This involved a sugarcane farm, homestead, and farm shed housing farm machinery, which were typical of those found in sugarcane farming districts in tropical Queensland. This environment was based on photographs and images from magazines supplied by the project team; its development involved an iterative process, between the builders and the project team, of checking, commenting on, and modifying details to ensure their relevance and accuracy.

4. The Top Dingo team acted the scenes depicted in the storyboards through the avatars they had created. The action was captured through screen capture software and scenes were shot from a number of angles as with a normal video using human actors. The soundtrack was spaced so that the recorded voices matched the video footage; foley (sound effects), such as the sound of car tires on a gravel road, were added to make the soundtrack more realistic; opening and closing credits were created; and the resulting product was edited into a single coherent video.

5. The final draft form of the product was uploaded to YouTube (limited access) for viewing, comment and, finally, approval by the research team. 


\section{VIRTUAL WORLD TOOLS EVALUATION}

The project takes an iterative research design-based approach [34] to evaluate and incrementally improve the digital discussion support tools, thereby optimizing their value to on-farm operational decision-making. This methodology is a blend of empirical research with the theorybased design of learning environments [35]. The method involves the systematic investigation of innovations designed to improve educational practice through an iterative process of design, development, implementation, and analysis in real-world settings [36], and follows the framework outlined in Fig. 2. A major strength of designbased research lies in its ability to adjust or adapt the intervention based on feedback from participants.

\section{A. First iteration}

Members of the USQ research team, along with USQ Distance Learning personnel, originally trialed the virtual world discussion support tool concept in an Asia-Pacific Network funded project focused on climate risk management on cotton farms in Andhra Pradesh, a major farming region in eastern India $[7,8]$.

Based on discussions with end-users and colleagues from Acharya N.G. Ranga Agricultural University (ANGRAU) in Hyderabad, Tamil Nadu Agricultural University in Coimbatore, and the Indian Meteorological Department, key climate information relevant to on-farm decisions in local farming regions was identified. This was incorporated into contextually-relevant simulated discussions, from which a Second Life machinima (Fig. 3) was created by members of the project team.

Versions of the video were made in Telugu (the language of the region), Hindi, and English. Students from Andhra Pradesh, who were studying at USQ and were native speakers of Telugu and Hindi, were recruited for the video production in order to provide locally relevant languages and accents that would be familiar to farmers in Andhra Pradesh.

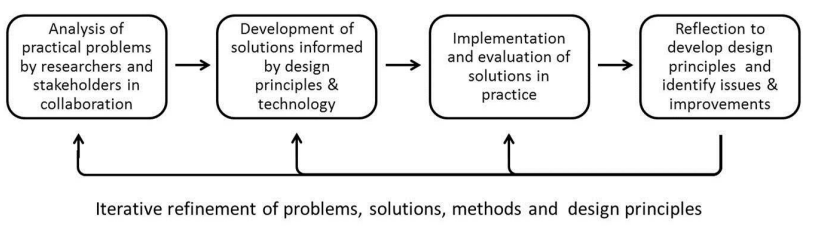

Figure 2. Design-based research approach (after Reeves, 2006)

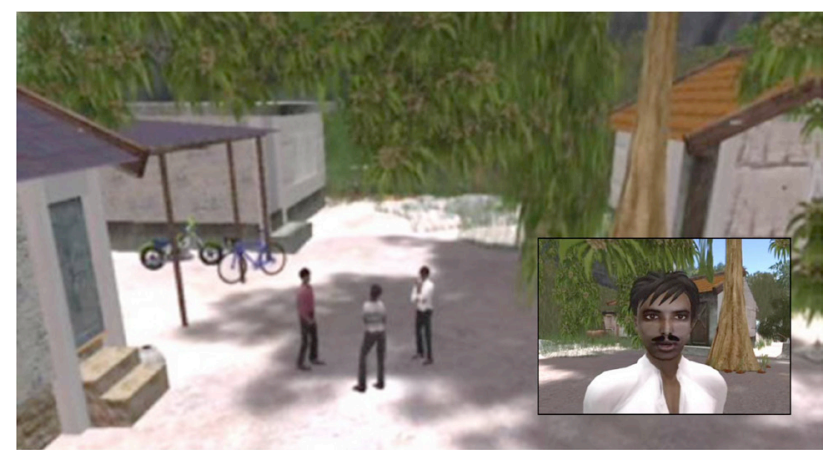

Figure 3. Screen shot of the agri-climate discussion support machinima developed for cotton farmers in Andra Pradesh, India, showing the contextualized setting and culturally appropriate avatars.
The video was viewed during workshops in India and responses sought from farmers present. While the science content regarding climate forecasts and implications for farming was seen to be very useful, feedback identified the need for the video to provide a more realistic depiction of the local farmers (e.g. age, clothing) and village (e.g. bicycles, chickens, numbers of people) in order to better convey a "real-world" setting [7,8].

The study indicated that greater attention to detail in the production of the videos is vital if this discussion-support approach is to be acceptable to farmers, and viable in the longer-term [7]. The learnings from the APN funded project informed the next (current) iteration of these agriclimate discussion support tools.

\section{B. Second iteration}

The "Sweet Success" project initially developed a prototype sugar cane harvesting scenario machinima, informed by the findings of the APN-funded Indian cotton farming project, using the process described in Sections IIB and IIC above. Once developed, this machinima (Fig. 4) was shown to a small focus group of 17 sugar cane farmers, extension officers, and industry personnel. Individuals then responded to a series of questions through a semi-structured questionnaire. Data collected included responses to the machinima, details of climate information delivery needs, and demographic information. Interviewees were also asked to rate the value of the tool in "supporting canefarmers to take some action, small or large, in relation to the information presented".

Overall, responses to the machinima were positive. A small number of participants expressed a preference for the use of real people rather than animated characters; however, most identified readily with the characters and settings depicted in the machinima, and felt the machinima accurately captured the essence of a typical canefarmer "shed meeting". Key messages identified by the participants were consistent with the informational objectives of the machinima script.

Across the stakeholder groups represented, participants confirmed that machinima would provide a useful tool to support discussion of climate risk as well as other industry issues. Challenges identified were: (i) to ensure that the information presented in the machinima scripts was suitably targeted to ensure audience engagement with the modeled discussion; and (ii) the need for the tools to provide a seamless link between current climate forecasts and modeled discussions about specific decisions.

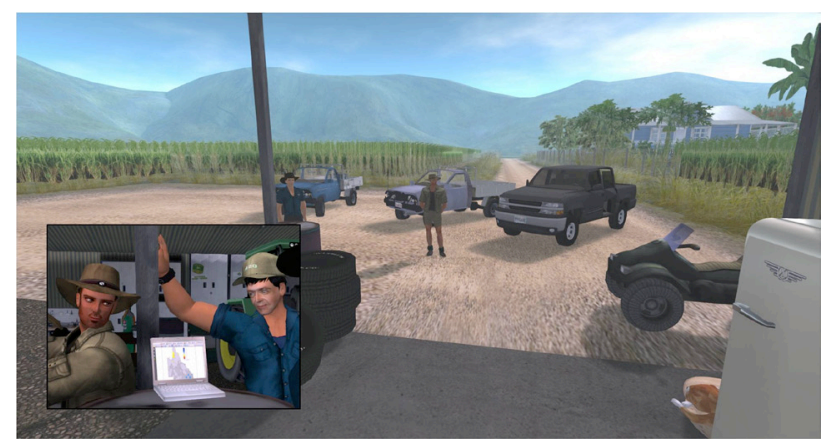

Figure 4. Screen shot of the agri-climate discussion support machinima developed for Australian sugar cane farmers showing a typical Queensland sugar cane farming landscape, farm vehicles, house, farm shed and avatars dressed and behaving in ways designed to appear familiar to sugar cane farmers viewing the machinima. 


\section{Third iteration}

Following the pilot evaluation, four final cane farming machinima have now been created, incorporating the feedback from the pilot harvesting machinima evaluation. These are (i) an irrigation scenario; (ii) a fertilizer application scenario; (iii) a revised version of the harvesting scenario; and (iv) a family discussion. Evaluation of these four final machinima will be conducted using two different approaches. One of these will involve a series of three or four workshops in cane growing regions of coastal Queensland; at each workshop the machinima will be shown as a stimulus for discussion. Responses to the machinima will be collected from individual workshop participants, using a semi-structured interview format, and analyzed thematically. This approach is designed to investigate participants' responses to the discussion support tools as stimuli for the ensuing discussion in the workshop environment.

The second assessment will be run through the CANEGROWERS organization website, with the 4,000 CANEGROWERS members invited to view the machinima and complete an online questionnaire. This survey will capture responses to the machinima as well as the social profiles of landholders based on key characteristics associated with perceptions and values (after [37]), including: length of farm occupancy, farm size, farm diversification, and landholder values attached to place, as well as personal experience of climate extremes and current integration of climate information in farm planning and decision-making. This approach is designed to investigate participants' responses to observing the discussions modeled in the machinima in an online environment.

Analysis of responses to the machinima as discussion support tools will explore issues associated with the usefulness and ease of use of the tools in relation to technology type, risk profile, and gender (e.g. [38]) and users' experience and satisfaction with the virtual world environment (e.g. [39]).

\section{POTENTIAL APPLICATIONS}

There is a critical need for integrated knowledge networks to support the development of more resilient agricultural systems to cope with the uncertainties and complexities of future climate scenarios [40]. Increasing climate variability with climate change, in combination with population growth and increasing scarcity of resources, is likely to cause significant biophysical, environmental, social, and economic disruption, not least in the agricultural sector [40].

Fundamental to building farming systems which are resilient to climate variability is targeted climate forecasts which are relevant to a farmer's location and farming experience [7, 41]. Significant advances in climate science in recent decades, based on improved understanding of ocean-atmosphere interactions, now permit climate predictions at seasonal to inter-annual timescales [42]. This information, in combination with spatial downscaling, is critical to helping decision makers in the agricultural sector deal more effectively with the effects of climate variability [43]. Ongoing need exists for: further improvements in the accuracy of models at scales which are relevant to agricultural decision-making; involving stakeholders more actively in the development of climate forecast tools for agricultural risk management; responding to specific cli- mate information needs of diverse groups of end users; and giving greater priority to extension and communication activities [43].

The approach described in this paper, once operationalized, represents a significant opportunity for the rapid and cost-effective dissemination of relevant climate information as it is developed. On-line discussion support tools such as "Sweet Success" will enhance knowledge sharing, capacity building, and learning opportunities for farmers and land managers at a scale not able to be realised by conventional extension and outreach activities due to issues such as physical accessibility, time, and cost. In Australia, these flexible learning tools will also potentially be able to use the increased capacity for internet access in rural areas should the Australian Government's proposed National Broadband Network (NBN) eventuate.

Options which enable online discussion may also be developed, as may scheduled events such as virtual world shed meetings and field days hosted in contextualized environments. These would better enable farmers who are geographically separated to connect with each other and with cropping and climate experts from anywhere in the world (along the lines of the virtual classroom; e.g. Gregory et al. [22]). Targeted climate information, machinima, and virtual field days/workshops may be hosted on a web portal also accessible by a range of mobile digital devices. This becomes increasingly viable with more widespread and affordable internet and mobile access.

This innovative online virtual group discussion environment is expected to provide both more equitable access to agricultural extension, as well as improved learning and decision-making opportunities. It has significant advantages over traditional shed meetings: farmers will be able to access expertise and participate in discussions regardless of where they live; and will ease the time and cost burden of real-world meetings while still allowing for the discussion, participation, and interaction associated with those meetings.

These tools have potential to transform the delivery of extension services. They will complement conventional agricultural extension and outreach programs with new options for real-time information exchange at local, regional, national, and even global scales. They will enable farmers to access experts and organize their own meetings, thereby enhancing needs-based rapid and effective real-time knowledge sharing, capacity building, and online learning opportunities within the agricultural sector. They will also provide increasing opportunity for discussion around risk, decision-making, and implementation of sustainable farming practices. At the same time, they will build the profile of agricultural industries as lead innovators in blended digital and "in person" extension and outreach.

Further, the development and deployment of regionallytargeted web-based "virtual" discussion-support systems, that integrate climate variability and climate change (at a range of scales) with practical farming operations for particular agricultural systems, is increasingly feasible across many parts of the world. For example, while access in rural areas may be a limitation in some regions [44], initiatives such as that of the Indian Government, which is providing thousands of computer terminals and facilities ('internet kiosks') across regional India, represent enormous opportunity and the operational vehicle for web- 
based initiatives such as this. Improved internet access, as well as tremendous uptake of mobile technologies and handheld devices such as smart phones and tablets, means new opportunities to use digital platforms in the widespread and cost-effective delivery of extension services.

Based on the research team's experience to date in developing and evaluating virtual world machinima as discussion support tools for farmers in both India and Australia, it is believed there is considerable scope for further development of this approach for farming regions and systems globally. The approach has been presented at UN WMO Commission for Agricultural Meteorology workshops and meetings, where it has received enthusiastic support (Stone, pers. com.). There is increasing recognition globally that improved climate risk decision-making and management in agriculture, supported by in-time access to relevant climate information, are fundamental to ensuring future global food security and enhancing the well-being and long-term sustainability of farming communities [7].

\section{ACKNOWLEDGMENT}

This work is supported by the Digital Futures (CRN) Project funded through the Australian Government's Collaborative Research Networks program. It also receives valuable in-kind support from Matt Kealley and CANEGROWERS Australia.

\section{REFERENCES}

[1] World Resources Institute, Creating a Sustainable Food Future. A Menu of Solutions to Sustainably Feed More Than 9 Billion People by 2050. World Resources Report 2013-14: Interim Findings. Washington DC: World Resources Institute, 2013.

[2] A. Bisaro, S. Wolf and J. Hinkel, "Framing climate vulnerability and adaptation at multiple levels: addressing climate risks or institutional barriers in Lesotho?" Climate and Development, vol. 2(2), pp. 161-175, 2010. http://dx.doi.org/10.3763/cdev.2010. $\underline{0037}$

[3] K. D. Warner, "Extending agroecology: grower participation in partnerships is key to social learning." Renewable Agriculture \& Food Systems, vol. 21(2), pp. 84-94, 2006. http://dx.doi.org/10.1079/RAF2005131

[4] C. A. Francis and H. C. Carter, "Participatory education for sustainable agriculture: everyone a teacher, everyone a learner." J Sustain Agr, vol. 18(1), pp. 71-84, 2001. http://dx.doi.org/10.1300/J064v18n01 06

[5] B. E. Swanson, Global Review of Good Agricultural Extension and Advisory Service Practices. Rome, Italy: Food and Agriculture Organization of The United Nations (UN FAO), 2008.

[6] G. Leach, "Extension policy in Australia - challenges and solutions." In J. Jennings, R. Packham and D. Woodside (eds.), Shaping Change: Natural Resource Management, Agriculture and the Role of Extension. Australia: Australia Pacific Extension Network (APEN), pp. 207-215, 2010.

[7] 7. R. Stone, Web-based 'Discussion-support' Agricultural Climate Information for Regional India. Project: CBA2010-07NSY-Stone. Final Report submitted to APN. Asia-Pacific Network for Global Change Research (APN), 2010.

[8] R. C. Stone, S. Reushle and R. Reddy, (2012) "Web-based 'discussion-support' agricultural climate information for regiona India." APN Science Bulletin, vol. 2, pp. 55-58, 2012.

[9] R. L. McCown, "Locating agricultural decision support systems in the troubled past and socio-technical complexity of models for management." Agr Syst, vol. 74(1), pp. 11-25, 2002. http://dx.doi.org/10.1016/S0308-521X(02)00020-3

[10] R. L. McCown, Z. Hochman and P.S. Carberry, "Probing the enigma of the decision support system for farmers: learning from experience and from theory." Agr Syst, vol. 74(1), pp. 1-10, 2002. http://dx.doi.org/10.1016/S0308-521X(02)00021-5
[11] P. Hayman, "Decision support systems in Australian dryland farming: a promising past, a disappointing present and uncertain future." Decis Support Syst, vol. 4, p. 1, 2003.

[12] L. N. Jørgensen, E. Noe, A. M. Langvad, J. E. Jensen, J. E. Ørum and P. Rydahl, "Decision support systems: barriers and farmers' need for support." Bulletin OEPP/EPPO, vol. 37, pp. 374-377, 2007.

[13] R. A. Nelson, D. P. Holzworth, G. L. Hammer and P. T. Hayman, "Infusing the use of seasonal climate forecasting into crop management practice in north east Australia using discussion support software." Agr Syst, vol. 74(3), pp. 393-414, 2002. http://dx.doi.org/10.1016/S0308-521X(02)00047-1

[14] L. McKeown, "Overview of the breakthroughs in distance education systems." APN Workshop, ANGRAU University, Hyderabad, India, 28 September 2010 (unpublished).

[15] C. Morningstar and F. R. Farmer, "The lessons of Lucasfilm's Habitat." In M. Benedikt (ed.), Cyberspace: First Steps. Cambridge: MIT Press, 1991.

[16] M. L. Maher, "Designing the virtual campus." Design Studies, vol. 20(4), pp. 319-342, 1999. http://dx.doi.org/10.1016/S0142694X(98)00043-X

[17] T. Ritzema and B. Harris, "The Use of Second Life for distance education.” Journal of Computing Sciences in Colleges, vol. 23(6), pp. 110-116, 2008.

[18] Voyager, D. (2014, March 17). SL Metrics. Retrieved from http://danielvoyager.wordpress.com/sl-metrics/

[19] D. Leeming (ed.), A Dictionary of Asian Mythology (Oxford Reference Online ed.). London: Oxford University Press, 2001.

[20] L. Duridanov and S. Simoff, "'Inner Listening' as a basic principle for developing immersive virtual worlds." Online - Heidelberg Journal of Religions on the Internet, vol. 2(3), 2007.

[21] G. Salmon, "The future for (second) life and learning." Brit J Educ Technol, vol. 40(3), pp. 526-538, 2009. http://dx.doi.org/10.1111/ j.1467-8535.2009.00967.x

[22] S. Gregory, B. Dalgarno, M. Campbell, T. Reiners, V. Knox and Y. Masters, "Changing directions through VirtualPREX: engaging pre-service teachers in virtual professional experience." In Williams, G., Statham, P., Brown, N. and Cleland, B. (eds.). Changing Demands, Changing Directions. Proceedings ASCILITE, Hobart 2011. pp.491-501, 2011.

[23] W. Tsou, W. Wang and Y. Tzeng, "Applying a multimedia storytelling website in foreign language learning." Computers \& Education, vol. 47(1), pp. 17-28, August 2006. http://dx.doi.org/10.1016/j.compedu.2004.08.013

[24] K. Ryokai, C. Vaucelle and J. Cassell, "Virtual peers as partners in storytelling and literacy learning." J Comput Assist Lear, vol. 19(2), pp. 195-208, 2003. http://dx.doi.org/10.1046/j.02664909.2003.00020.x

[25] T. A. Abma, "Learning by telling: storytelling workshops as an organizational learning intervention." Manage Learn, vol. 34(2), pp. 221-240, 2003. http://dx.doi.org/10.1177/135050760303 $\underline{4002004}$

[26] H. Barrett, "Researching and evaluating digital storytelling as a deep learning tool." Society for Information Technology \& Teacher Education International Conference 2006, Orlando, Florida USA. Society for Information Technology \& Teacher Education, 2006.

[27] K. Kok, R. Biggs and M. Zurek, "Methods for developing multiscale participatory scenarios: insights from southern Africa and Europe." Ecology and Society, vol. 12(1), pp. 16, 2007.

[28] P. Lamarque, A. Artaux, C. Barnaud, L. Dobremez, B. Nettier and S. Lavorel, "Taking into account farmers' decision making to map fine-scale land management adaptation to climate and socioeconomic scenarios." Landscape Urban Plan, vol. 119, pp. 147157, 2013. http://dx.doi.org/10.1016/j.landurbplan.2013.07.012

[29] A. Singhal and E. M. Rogers, Entertainment-Education: A Communication Strategy for Social Change. Routledge, 2012.

[30] S. S. Taylor, D. Fisher and R. L. Dufresne, "The aesthetics of management storytelling: a key to organizational learning." Manage Learn, vol. 33(3), pp. 313-330, 2002. http://dx.doi.org/10.1177/1350507602333002

[31] A. Gesser-Edelsburg and A. Singh, "Enhancing the persuasive influence of entertainment-education events: rhetorical and 
aesthetic strategies for constructing narratives." Critical Arts, vol. $27(1)$ pp. 56-74, 2013. http://dx.doi.org/10.1080/ 02560046.2013 .766973

[32] P. Johnson, "Introduction: documenting virtual lLife in machinima." In P. Johnso \& D. Pettit (Eds.), Machinima: The Art and Practice of Virtual Filmmaking (pp. 1-15). Jefferson, NC: McFarland \& Co., 2012.

[33] D. B. Goldman, B. Curless, D. Salesin and S. M. Seitz, "Schematic storyboarding for video visualization and editing." ACM Transactions on Graphics (TOG), vol. 25(3), pp. 862-871, July 2006. http://dx.doi.org/10.1145/1141911.1141967

[34] T. C. Reeves, "Design research from a technology perspective." In J. van den Akker, K. Gravemeijer, S. McKenney and N. Nieveen (Eds.), Educational Design Research. London: Routledge, 2006, pp. 52-66.

[35] The Design-Based Research Collective, "Design-based research: an emerging paradigm for educational inquiry." Educational Researcher, vol. 32(1), pp. 5-8, 2003. http://dx.doi.org/10.3102/ 0013189X032001005

[36] F. Wang and M. J. Hannafin, "Design-based research and technology-enhanced learning environments." Educational Technology Research \& Development, vol. 53(4), pp. 5-23, 2005. http://dx.doi.org/10.1007/BF02504682

[37] I. Bohnet, "Assessing retrospective and prospective landscape change through the development of social profiles of landholders: a tool for improving land use planning and policy formulation." Landscape Urban Plan, vol. 88(1), pp. 1-11, 2008. http://dx.doi.org/10.1016/j.landurbplan.2008.07.002

[38] I. Im, Y. Kim and H.-J. Han, "The effects of perceived risk and technology type on users' acceptance of technologies." Information \& Management, vol. 45(1), pp. 1-9, January 2008. http://dx.doi.org/10.1016/j.im.2007.03.005

[39] T. Verhagen, F. Feldberg, B. van den Hooff, S. Meents and J. Merikivi, "Satisfaction with virtual worlds: an integrated model of experiential value." Information \& Management, vol. 48(6), pp. 201-207, 2011. http://dx.doi.org/10.1016/j.im.2011.02.004

[40] Australian Academy of Science. Agricultural Productivity and Climate Change. Theo Murphy High Flyers Think Tank 09, Oaks on Collins, Melbourne, 22-23 October 2009. Canberra ACT: Australian Academy of Science, 2010.

[41] J. W. Hansen, "Realizing the potential benefits of climate prediction to agriculture: issues, approaches, challenges." Agr Syst, vol. 74 (3), pp. 309-330, 2002. http://dx.doi.org/10.1016/ S0308-521X(02)00043-4

[42] R. C. Stone, G. L. Hammer and T. Marcussen, "Prediction of global rainfall probabilities using phases of the Southern Oscillation Index." Nature, 384(6606), pp. 252-255, 1996. http://dx.doi.org/10.1038/384252a0

[43] M. V. K. Sivakumar, "Climate prediction and agriculture: current status and future challenges." Climate Res, vol. 33(1), pp. 3, 2006. http://dx.doi.org/10.3354/cr033003

[44] H.-W. Kim, H. C. Chan and S. Gupta, "Value-based adoption of mobile internet: an empirical investigation." Decis Support Syst, vol. 43(1), pp. 111-126, February 2007. http://dx.doi.org/10.1016/ j.dss.2005.05.009

\section{AUTHORS}

Neil Cliffe is a PhD candidate with the Digital FuturesCollaborative Research Network (DF-CRN) at the University of Southern Queensland, Toowoomba QLD 4350 Australia (e-mail: Neil.Cliffe@usq.edu.au).

Joanne Doyle is a $\mathrm{PhD}$ candidate with the Digital Futures-Collaborative Research Network (DF-CRN) at the
University of Southern Queensland, Toowoomba QLD 4350 Australia (e-mail: Joanne.Doyle@usq.edu.au).

Helen Farley is a Senior Lecturer (Digital Futures) in the Australian Digital Futures Institute (ADFI) at the University of Southern Queensland, Toowoomba QLD 4350 Australia (e-mail: Helen.Farley@usq.edu.au).

Janette Lindesay is Associate Director Education \& Deputy Director in the Fenner School of Environment and Society at the Australian National University, Canberra ACT Australia (email: Janette.Lindesay@anu.edu.au).

Adam Loch is an Early Career Development Fellow in the School of Commerce, University of South Australia Business School, Adelaide SA Australia (e-mail: Adam.Loch@unisa.edu.au).

Tek Maraseni is a Research Fellow with the International Centre for Applied Climate Science (ICACS) at the University of Southern Queensland, Toowoomba QLD 4350 Australia (e-mail: Tek.Maraseni@usq.edu.au).

Torben Marcussen is a climate scientist with International Centre for Applied Climate Science (ICACS) at the University of Southern Queensland, Toowoomba QLD 4350 Australia (e-mail: Torben.Marcussen@usq.edu.au).

Neil Martin is a $\mathrm{PhD}$ candidate with the Digital Futures-Collaborative Research Network (DF-CRN) at the University of Southern Queensland, Toowoomba QLD 4350 Australia (e-mail: Neil.Martin@usq.edu.au).

Shahbaz Mushtaq is Director of Research and Senior Scientist with the International Centre for Applied Climate Science (ICACS) at the University of Southern Queensland, Toowoomba QLD 4350 Australia (e-mail: Shahbaz.Mushtaq@usq.edu.au).

Jenny Ostini is a Postdoctoral Research Fellow with the Digital Futures-Collaborative Research Network (DF$\mathrm{CRN}$ ) at the University of Southern Queensland, Toowoomba QLD 4350 Australia (e-mail: Jenny.Ostini@usq.edu.au).

Kathryn Reardon-Smith is a Postdoctoral Research Fellow (Climate Risk Management) with the Digital Futures-Collaborative Research Network (DF-CRN) at the University of Southern Queensland, Toowoomba QLD 4350 Australia (e-mail: Kathryn.ReardonSmith@usq.edu.au).

Roger Stone is a Professor in Climate Science and Director of the International Centre for Applied Climate Science (ICACS) at the University of Southern Queensland, Toowoomba QLD 4350 Australia. Professor Stone is also Program Leader for 'Climate Change/Variability and Natural Disasters in Agriculture' at the World Meteorological Organization Commission for Agricultural Meteorology and Expert Team Leader: WMO Commission for Climatology. (e-mail: Roger.Stone@usq.edu.au).

This article is an extended and modified version of a paper presented at ICELW 2014, the Seventh Annual International Conference on Elearning in the Workplace, held from June 11-13, 2014 in New York. Submitted 28 April 2014. Published as resubmitted by the authors 14 October 2014. 